\title{
Primary ovarian pregnancy with a levonorgestrel intrauterine system
}

\author{
Emmanuel Kalu, Stewart Disu, Hilary Gordon-Wright, Narendra Pisal
}

\section{Case report}

A 26-year-old woman, para $2+0$, presented to the accident and emergency department with vaginal bleeding and lower abdominal pain. Her symptoms followed the insertion of a levonorgestrel intrauterine system (LNG IUS) (Mirena ${ }^{\circledR}$ ) for contraception 13 weeks prior to presentation. She had continued to bleed irregularly since the insertion of the LNG IUS and had visited her general practitioner (GP) on two occasions when she was reassured that irregular vaginal bleeding and spotting are common side effects of the LNG IUS. She subsequently developed a constant, dull, lower abdominal pain and went to her GP who removed the LNG IUS and prescribed her a course of antibiotics.

The patient presented to the accident and emergency department when her pain did not subside after 1 week. A urine pregnancy test was positive and a quantitative serum beta human chorionic gonadotrophin $(\beta-\mathrm{hCG})$ subunit measurement was $33000 \mathrm{mIU} / \mathrm{ml}$. A transvaginal ultrasound scan showed a bulky, retroverted uterus with a heterogeneous endometrium measuring $19 \mathrm{~mm}$. There was no visible intrauterine pregnancy.

There was a complex mass in the pouch of Douglas, which measured $67 \times 36 \times 29 \mathrm{~mm}$. This was composed of the right ovary, containing a gestation sac and an embryo with a crown-rump length of $14 \mathrm{~mm}$, equivalent to a gestation of $7+6$ weeks. No fetal heartbeat pulsation was observed. The left ovary was normal. An ultrasound diagnosis of right ovarian ectopic pregnancy was made (Figure 1).

Laparoscopy confirmed a $5 \times 6 \mathrm{~cm}$ haemorrhagic mass in the right ovary. Both Fallopian tubes were normal as was the left ovary. The pouch of Douglas contained $150 \mathrm{ml}$ blood (Figure 2). Laparoscopic excision of the right ovarian cystic mass was complicated by significant bleeding. A laparotomy was therefore performed and the right ovarian mass was excised with conservation of the right ovary.

The patient made a good postoperative recovery and was discharged after 3 days. The serum $\beta$-hCG level dropped from 33000 to $2000 \mathrm{mIU} / \mathrm{ml}$ and thereafter to 10 $\mathrm{mIU} / \mathrm{ml}$ after 4 weeks.

Histology confirmed sections of ovary showing several chorionic villi of the first-trimester type associated with an implantation site reaction by trophoblasts. Haemorrhage was evident within the ovary, which also contained a recent corpus luteum in keeping with ovarian pregnancy.

J Fam Plann Reprod Health Care 2006; 32(4): 253-254

(Accepted 20 January 2006)

Assisted Conception Unit, St Helier Hospital, Carshalton, UK Emmanuel Kalu, MRCOG, DFFP, Clinical Research Fellow

Elizabeth Garrett Anderson and Obstetric Hospital, University College London Hospitals, London, UK

Stewart Disu, MB BS, DFFP, Specialist Registrar

Women's Health Department, The Whittington Hospital, London, UK

Hilary Gordon-Wright, MSc. MRCOG, Associate Specialist

Narendra Pisal, MD, MRCOG, Consultant

Correspondence to: Dr Emmanuel Kalu, Assisted Conception Unit, St Helier Hospital, Wrythe Lane, Carshalton, Surrey SM5 1AA, UK. E-mail: ekalu@doctors.org.uk

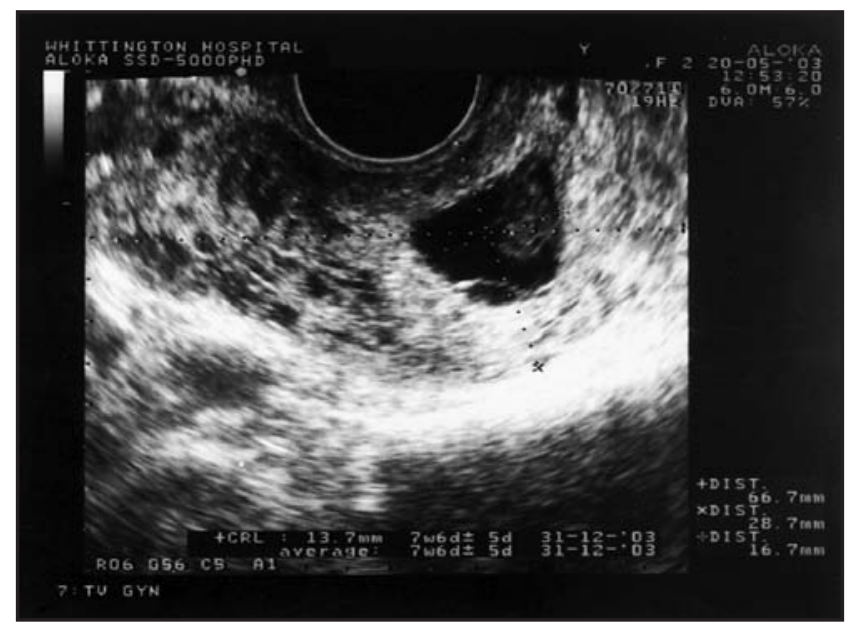

Figure 1 Transvaginal ultrasound scan showing a gestation sac and embryo in the right ovary

The patient was seen in clinic 6 weeks post-surgery and has made a good recovery.

\section{Discussion}

Ectopic pregnancy can pose diagnostic difficulties, especially when it occurs with a LNG IUS in situ. Eightyfive percent of ectopic pregnancies with intrauterine contraceptive devices (IUDs) were misdiagnosed on the patient's first visit. ${ }^{1}$ Diagnostic difficulties can arise when early symptoms of ectopic pregnancy are attributed to the side effects of LNG IUS. Following insertion of LNG IUS, the first few months are characterised by an increase in bleeding days. Five percent of women will be amenorrhoeic after 2 months. ${ }^{2}$ Lower abdominal discomfort may occur in the days following insertion, although subsequent pain usually indicates pathology.

Our patient presented to her GP twice with the above mentioned symptoms and was reassured since such symptoms are not uncommon with the LNG IUS. The possibility of ectopic pregnancy was clearly not considered.

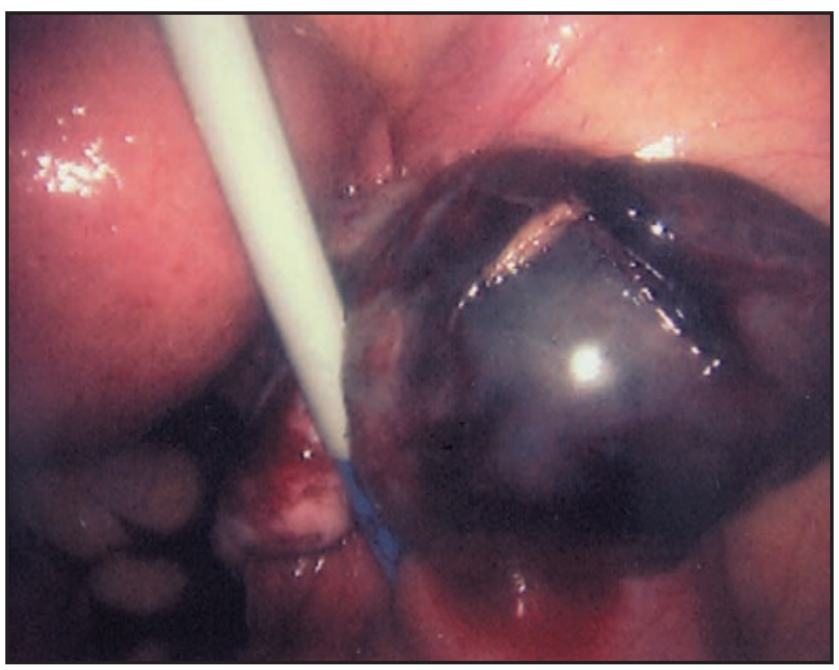

Figure 2 Laparoscopic image of a right ovarian ectopic pregnancy 
Although the LNG IUS is a very effective form of contraception (with a cumulative pregnancy rate of 1.1 per 100 woman-years at 7 years $^{3}$ ), the possibility of an ectopic pregnancy should always be considered - especially when a woman of reproductive age presents with abdominal pain - as this occurs in 0.06 per 100 woman-years. ${ }^{4}$

Primary ovarian pregnancy is a rare form of ectopic pregnancy occurring in 1 in 40000 deliveries..$^{5}$ It is relatively more frequent in IUD users, in whom it accounts for 1 in 7-9 ectopic pregnancies. ${ }^{6}$

Ultrasound diagnosis of ovarian pregnancies is rare. ${ }^{6}$ The development of transvaginal ultrasound, together with the availability of a highly specific radioimmunoassay technique for the detection of hCG, has made diagnosis of ovarian pregnancy possible. In the present case an embryo with a measurable crown-rump length was visualised by transvaginal ultrasound scan in the right ovary (Figure 1).

Treatment for ovarian ectopic pregnancy may be medical (methotrexate) or surgical (laparoscopy and laparotomy) abortion. Shamma et al. ${ }^{7}$ successfully treated primary ovarian pregnancy with methotrexate. Whereas there exist clear-cut criteria for the management of tubal ectopic pregnancy with methotrexate, the role of medical management in ovarian ectopic pregnancy remains to be defined.

Surgical therapy ranges from oophorectomy, ovarian wedge resection or excision of the ovarian cystic mass with conservation of the ovary. Improvements in operative laparoscopy have led many surgeons to perform conservative ovarian surgery much more frequently than in the past. ${ }^{8}$ The women concerned are generally young and may wish to retain their reproductive capability. Seinera et al. ${ }^{8}$ successfully managed primary ovarian ectopic pregnancies by laparoscopic excision of healthy ovarian tissue in addition to the gestation sac. There is little justification for expanding the surgical procedure beyond the removal of the gestation sac. Laparoscopy involves a shorter hospital stay and allows the patient to resume normal activities within a short period of time. Furthermore, the low risk of adhesion formation that usually accompanies laparoscopic procedures is a major factor as regards reproductive prognosis.

Although laparoscopic management may be associated with these clear benefits, "to the practising physician, it is of greater importance to reach a decision regarding the necessity for laparotomy". 8 We reached this decision in our patient when laparoscopic excision was associated with significant intraoperative bleeding. Surgery was, however, still conservative with excision of the ovarian gestation sac and conservation of the remainder of the ovary.

\section{Statements on funding and competing interests \\ Funding. None identified.}

Competing interests. None identified.

\section{References}

1 Hallatt J. Primary ovarian pregnancy: a report of twenty-five cases. Am J Obstet Gynecol 1982; 143: 55-60.

2 Zalel Y, Gamzu R, Shulman A, Achiron R, Schiff G, Lidor A. The progestative effect of the levonorgestrel-releasing intrauterine system - when does it manifest? Contraception 2003; 67: 47.

3 Sivin I, Stern J, Coutinho E, Mattos C, El Mahgoub S, Diaz S, et al. Prolonged intrauterine contraception: a seven-year randomised study of the levonorgestrel $20 \mathrm{mcg} / \mathrm{day}$ and the Copper T380 Ag IUDs. Contraception 1991; 44: 473-480.

4 Schering Health Care Limited. Mirena: Summary of Product Characteristics. http://emc.medicines.org.uk [Accessed 20 December 2005].

5 Lehfeldt $\mathrm{H}$, Tietz C, Gorstien F. Ovarian pregnancy and the intrauterine device. Am J Obstet Gynecol 1970; 108: 1005.

6 Sergent F, Mauger-Tinlot F, Gravier A, Verspyck E, Marpeau L. Ovarian pregnancies: revaluation of diagnostic criteria [in French]. J Gynecol Obstet Biol Reprod (Paris) 2002; 31: 741-746.

7 Shamma F, Schwartz L. Primary ovarian pregnancy successfully treated with methotrexate. Am J Obstet Gynecol 1992; 169: 1362-1363.

8 Seinera P, Di Gregorio A, Arisio R, Decko A, Crana F. Ovarian pregnancy and operative laparoscopy; a report of eight cases. Hum Reprod 1997; 12: 608-610.

\section{FACULTY AWARDS}

The Faculty of Family Planning and Reproductive Health Care has available a number of annual awards for which applications are invited from Faculty members and non-members as listed below. Details of the individual awards, together with an application form and/or guidelines on how to apply and any eligibility criteria, may be found on the Faculty website at www.ffprhc.org.uk.

\section{Margaret Jackson Prize Essay}

Award: Three prizes awarded annually for the best essays on a topic related to contraceptive and sexual health care. The first prize is $£ 300$, with $£ 100$ each for the two runners-up.

Eligibility: Individuals (undergraduate medical students)

Closing date: 24 March annually

\section{The David Bromham Annual Memorial Award}

Award: Prize awarded for a piece of work which through inspiration, innovation or energy has furthered the practice of family planning and reproductive health care in any way and any setting.

Eligibility: Individuals (Faculty members) or teams

Closing date: 7 April annually

\section{International Travelling Scholarship of the Faculty}

Award: Scholarship up to the value of $£ 2000$ to fund travel abroad to visit international colleagues, services, research or educational establishments to learn about some aspect of family planning or reproductive health care.

Eligibility: Individuals (Faculty members)

Closing date: 7 April annually

\section{The 4-0-8 Sheffield Fund}

Award: Approximately $£ 1000$ will be allocated every 3 months, either as a single award or divided between the successful applicants, for the purpose of funding training for health care professionals who have limited funding for attending training meetings.

Eligibility: Individuals (Faculty members/non-members)

Closing date: See website for details 